\title{
Influence of Age on the Relationship between Alcohol Consumption and Metabolic Syndrome
}

\author{
Ichiro Wakabayashi \\ Department of Environmental and Preventive Medicine, Hyogo College of Medicine, Hyogo, Japan
}

\section{Key Words}

Alcohol consumption - Atherosclerotic disease $\cdot$ Diabetes mellitus · Elderly $\cdot$ Hypertension • Lipid disorder •

Metabolic syndrome

\begin{abstract}
Background: Relationships between alcohol consumption and risks for metabolic syndrome in general populations are very controversial. It is unknown whether age influences the relationship between alcohol intake and the prevalence of metabolic syndrome. Objective: The purpose of this study was to determine whether age influences the relationship between alcohol consumption and metabolic syndrome. Methods: Men aged $\geq 35$ and $<45$ years (younger group) and those aged $\geq 65$ years (older group), matched for alcohol intake and smoking history, were divided into four subgroups by alcohol intake [non-, light ( $<22 \mathrm{~g}$ ethanol/day), heavy ( $\geq 22$ and $<44 \mathrm{~g}$ ethanol/day) and very heavy ( $\geq 44 \mathrm{~g}$ ethanol/day) drinkers]. Odds ratios (ORs) versus nondrinkers for each risk factor and metabolic syndrome were compared between the younger and older groups. Results: Both in the younger and older groups, ORs for high blood pressure and low HDL cholesterol were significantly high and low, respectively, in all drinker groups. In younger subjects, the OR for large waist circumference was significantly low in light drink-
\end{abstract}

ers, and the $O R$ for high hemoglobin $A_{1 c}$ was significantly low in light and heavy drinkers, while these associations were not found in older subjects. The OR for metabolic syndrome was significantly low in light and heavy drinkers in the younger subjects but was not significant in any drinker groups in older subjects. Conclusion: Age influences the relationships between alcohol consumption and atherosclerotic risk factors, and there is a significant association between alcohol intake and a lower risk for metabolic syndrome in young men but not in elderly men.

Copyright $\odot 2011$ S. Karger AG, Basel

\section{Introduction}

Habitual alcohol drinking has both beneficial and harmful actions on the pathogenesis of atherosclerotic cerebro- and cardiovascular diseases, and these alcohol actions depend on the amount of its consumption. Light to moderate drinking reduces risks for ischemic heart disease and thrombotic stroke mainly through altering the blood lipid profile and coagulation-fibrinolysis balance [1-3], while heavy drinking increases the risk for hemorrhagic stroke, mainly through induction of hypertension $[4,5]$. However, there are inconsistencies in results of previous studies on the relationship between al-

\section{KARGER \\ Fax +41613061234 E-Mail karger@karger.ch} www.karger.com

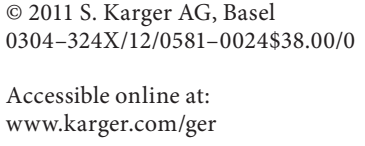

Ichiro Wakabayashi, $\mathrm{MD}, \mathrm{PhD}$

Department of Environmental and Preventive Medicine

Hyogo College of Medicine

Mukogawa-cho 1-1, Nishinomiya, Hyogo 663-8501 (Japan)

Tel. +81 79845 6561, Fax +81 79845 6563, E-Mail wakabaya @ hyo-med.ac.jp 
cohol drinking and metabolic syndrome, a multiplex risk factor that consists of several risk correlates of metabolic origin, such as dyslipidemia, hypertension and hyperglycemia. The relationship between alcohol drinking and metabolic syndrome has been reported to be inversely linear [6], J- or U-shaped [7], positively linear [8] and not significant [9]. In addition to gender and ethnic differences, a difference in age of subjects in these studies is a possible reason for the above discrepant findings on the relationship between alcohol drinking and metabolic syndrome. The prevalence of metabolic syndrome as well as blood pressure and blood lipid levels is influenced by age [10-12]. However, it is unknown whether and how the relationships of alcohol drinking with metabolic syndrome and related atherosclerotic risk factors are changed by age. Moreover, there have been only a few studies on the relationship between alcohol drinking and metabolic syndrome in the elderly.

The purpose of this study was, therefore, to determine whether the relationship between alcohol intake and metabolic syndrome is influenced by age. For this purpose, the prevalence of metabolic syndrome and related risk factors for atherosclerosis were compared between younger ( $\geq 35$ and $<45$ years old) and older ( $\geq 65$ years old) subject groups. There are two major sets of international criteria by the International Diabetes Federation (IDF) [13] and the National Cholesterol Education Program Adult Treatment Panel III (NCEP ATP III) [14] that are used to define metabolic syndrome. Both of these sets of criteria were used in this study to investigate the relationship between alcohol drinking and metabolic syndrome.

\section{Methods}

\section{Subjects}

The subjects were male workers aged $\geq 35$ and $<45$ years (younger group) and aged $\geq 65$ years (older group) (1,390 subjects in each group) who had received periodic health examinations at workplaces in Yamagata Prefecture in Japan. All of the subjects were of Japanese origin. The younger and older groups were adjusted for alcohol intake and smoking history. A cross-sectional study was performed using a local population-based database for the above subjects. This study was approved by the Ethics Committee of Yamagata University School of Medicine.

The average alcohol consumption of each subject per week was reported on questionnaires during health examinations at each workplace. Frequency and amount of habitual alcohol drinking were asked in the questionnaire as 'How frequently do you drink alcohol?' and 'What amount of alcohol per day do you drink on average?' Frequency of weekly alcohol drinking was categorized as 'every day', 'sometimes' and 'never'. Only regular drinkers who answered 'every day' were used as drinkers for analysis in this study, since it is difficult to know the correct average alcohol consumption of occasional drinkers. Usual daily alcohol consumption was calculated in terms of the equivalent number of 'go', a traditional Japanese unit of amount of sake (rice wine). The amounts of other alcoholic beverages, including beer, wine, whisky and shochu (traditional Japanese distilled spirit), were converted and expressed as units of 'go'. One go approximately corresponds to $180 \mathrm{ml}$ of sake, $500 \mathrm{ml}$ of beer, $240 \mathrm{ml}$ of wine, $60 \mathrm{ml}$ of whisky, and $80 \mathrm{ml}$ of shochu. The amount of daily alcohol drinking was categorized as 'null', 'less than 1 go per day', ' 1 go or more and less than 2 go per day', ' 2 go or more and less than 3 go per day', and ' 3 go or more per day'. One 'go' contains about $22 \mathrm{~g}$ of ethanol, and this amount was used to separate heavy drinkers from light drinkers since it is generally accepted that alcohol intake should be reduced to $<30 \mathrm{ml}$ or $20-30 \mathrm{~g}$ /day from the viewpoint of prevention of hypertension $[15,16]$. Average daily alcohol intake (grams of ethanol per day) was then calculated. The subjects were divided into four groups according to ethanol consumption per day (nondrinkers; light drinkers: $<22 \mathrm{~g}$ ethanol/ day; heavy drinkers: $\geq 22$ and $<44 \mathrm{~g}$ ethanol/day; very heavy drinkers: $\geq 44$ g ethanol/day). History of cigarette smoking was also surveyed by questionnaires. The categories of smokers in the questionnaire were nonsmokers, light smokers ( $<20$ cigarettes/ day), heavy smokers (20-39 cigarettes/day), and very heavy smokers ( $\geq 40$ cigarettes/day). Subjects who were receiving treatment for any illness were requested to state the names of diseases in a questionnaire at the health checkup.

\section{Measurements}

Height and body weight were measured with light clothes at the health checkup. Body mass index (BMI) was calculated as weight in kilograms divided by the square of height in meters. Waist circumference was measured at the navel level according to the recommendation of the definition of the Japanese Committee for the Diagnostic Criteria of Metabolic Syndrome [17]. In this study, the highest BMI level of subjects was 45.2 , and subjects showing very high BMI levels $(\geq 35)$ were only $0.54 \%(n=15)$ of the total subjects. Thus, extreme obese subjects were rare in subjects of this study, and measurement of waist circumference at the navel level may be accepted in this study. Blood pressure was measured by trained nurses, who were part of the local health-checkup company, with a mercury sphygmomanometer once on the day of the health checkup after each subject had rested quietly in a sitting position. Korotkoff phase $\mathrm{V}$ was used to define diastolic pressure. Fasted blood was sampled from each subject, and serum HDL cholesterol and triglycerides were measured by enzymatic methods using commercial kits, chorestest N-HDL and pureauto S TG-N (Sekisui Medical Co., Ltd., Tokyo, Japan), respectively. Hemoglobin $\mathrm{A}_{1 \mathrm{c}}\left(\mathrm{HbA}_{1 \mathrm{c}}\right)$ was determined by the latex cohesion method using a commercial kit (Determiner $\mathrm{HbA}_{1 c}$; Kyowa Medex, Tokyo, Japan). Coefficients of variation for reproducibility of each measurement were $\leq 5 \%$ for HDL cholesterol, $\leq 3 \%$ for triglycerides and $\leq 5 \%$ for $\mathrm{HbA}_{1 \mathrm{c}}$.

\section{Criteria of Metabolic Syndrome}

The variables of risk factors for atherosclerosis evaluated in this study were waist circumference, blood pressure, HDL cholesterol, triglycerides, and $\mathrm{HbA}_{1 \mathrm{c}}$. Two different sets of criteria were used separately for diagnosis of metabolic syndrome. Metabolic 
syndrome was defined, according to the criteria by IDF [13] with a slight modification, as the presence of 2 or more risk factors in addition to visceral obesity (waist circumference: $\geq 85 \mathrm{~cm}$ ) or was defined, according to the criteria by NCEP-ATP III [14], as the presence of 3 or more risk factors. Waist circumference of $85 \mathrm{~cm}$ for Japanese men has been reported to be a cut-off point yielding the maximal sensitivity plus specificity for predicting the presence of two or more components of metabolic syndrome [18, 19]. Risk factors included in the criteria are high blood pressure, dyslipidemia (low HDL cholesterol and/or high triglycerides) and hyperglycemia. Instead of fasting blood glucose, $\mathrm{HbA}_{1 \mathrm{c}}$, which is more sensitive for diagnosis of hyperglycemia than is fasting glucose, was used in this study. The criterion for each risk factor was defined as follows: high blood pressure, systolic blood pressure $\geq 130 \mathrm{~mm} \mathrm{Hg}$ and/or diastolic blood pressure $\geq 85 \mathrm{~mm} \mathrm{Hg}$; low HDL cholesterol, HDL cholesterol $<40 \mathrm{mg} / \mathrm{dl}$; high triglycerides, triglycerides $\geq 150 \mathrm{mg} / \mathrm{dl}$; high $\mathrm{HbA}_{1 \mathrm{c}}, \mathrm{HbA}_{1 \mathrm{c}}>5.8 \%$. In Japan, $\mathrm{HbA}_{1 \mathrm{c}}$ level of $5.8 \%$ measured by using methods standardized by the Japan Diabetes Society is generally used as a cut-off value for impaired glucose tolerance as well as impaired fasting glucose. In a previous study, the receiver-operated characteristic curve of $\mathrm{HbA}_{1 \mathrm{c}}$ in subjects with fasting plasma glucose levels of $\geq 100 \mathrm{mg} /$ dl showed that $\mathrm{HbA}_{1 \mathrm{c}}$ level of $5.8 \%$ was the most suitable cut-off value (sensitivity of $80.4 \%$ and specificity of $79.3 \%$ ) for diagnosis of impaired glucose tolerance (plasma glucose level of $\geq 200 \mathrm{mg}$ / $\mathrm{dl}$ at $2 \mathrm{~h}$ after oral ingestion of $75 \mathrm{~g}$ glucose) [20]. Subjects receiving treatment for hypertension, dyslipidemia and diabetes were also included in the above definitions of risk factors.

\section{Statistical Analysis}

Statistical analyses were performed using a computer software program (SPSS version 16.0 J for Windows, Chicago, Ill., USA). Mean values of each variable in the younger and older subject groups were compared using Student's unpaired t test. Mean values of each variable in the four alcohol groups were compared using analysis of variance (ANOVA) and subsequent Scheffé's Ftest. The percentages of drinkers, smokers, and subjects receiving therapy for hypertension, dyslipidemia or diabetes and the prevalence of each risk factor for atherosclerosis or metabolic syndrome were compared between each group pair using the $\chi^{2}$ test for independence. In logistic regression analysis, the odds ratios (ORs) of each drinker group vs. the nondrinker group for each risk factor for atherosclerosis or metabolic syndrome were calculated. ORs for high blood pressure, low HDL cholesterol, high triglycerides and high $\mathrm{HbA}_{1 \mathrm{c}}$ were calculated after adjustment for age, BMI and history of smoking. ORs for large waist circumference and metabolic syndrome were calculated after adjustment for age and history of smoking. p values $<0.05$ were defined as significant.

\section{Results}

\section{Comparison of Each Variable in the Younger and Older Subject Groups}

Table 1 shows profiles of younger and older subject groups matched for status of alcohol intake and status of smoking. Percentages of subjects with histories of therapy for hypertension, dyslipidemia and diabetes mellitus
Table 1. Profiles of the younger and older subject groups

\begin{tabular}{lcc}
\hline Variable & Younger & Older \\
\hline Number of subjects & $1,390(100 \%)$ & $1,390(100 \%)$ \\
Age, years & $39.5 \pm 2.9$ & $68.6 \pm 4.0^{* *}$ \\
Percentage of drinkers & 65.3 & 65.3 \\
Percentage of smokers & 35.6 & 35.6 \\
Therapy for hypertension, \% & 4.4 & $36.7^{* *}$ \\
Therapy for dyslipidemia, \% & 1.4 & $8.3^{* *}$ \\
Therapy for diabetes mellitus, \% & 1.6 & $7.0^{* *}$ \\
BMI & $23.66 \pm 3.68$ & $23.38 \pm 2.79^{*}$ \\
Waist circumference, cm & $83.2 \pm 9.6$ & $83.6 \pm 8.0$ \\
Systolic blood pressure, mm Hg & $126.1 \pm 15.1$ & $136.1 \pm 15.9^{* *}$ \\
Diastolic blood pressure, mm Hg & $76.6 \pm 11.5$ & $77.6 \pm 9.9^{*}$ \\
HDL cholesterol, mg/dl & $58.2 \pm 15.9$ & $56.1 \pm 15.5^{* *}$ \\
Triglycerides, mg/dl & $142.6 \pm 112.4$ & $129.9 \pm 110.3^{* *}$ \\
HbA ${ }_{1 c}$ \% & $4.99 \pm 0.69$ & $5.32 \pm 0.73^{* *}$ \\
\hline
\end{tabular}

Number of subjects, \% of drinkers, smokers or subjects receiving therapy, and means with standard deviations of each variable are shown. Asterisks denote significant differences from the younger group $\left({ }^{*} \mathrm{p}<0.05 ;{ }^{* *} \mathrm{p}<0.01\right)$.

were significantly higher in the older group than in the younger group. BMI was slightly but significantly lower in the older group than in the younger group, while there was no significant difference in waist circumference between the groups. Systolic and diastolic blood pressure was significantly higher in the older group than in the younger group. HDL cholesterol and triglycerides were significantly lower in the older group than in the younger group, while $\mathrm{HbA}_{1 c}$ was significantly higher in the older group than in the younger group.

\section{Comparison of Means of Each Variable among the Alcohol Intake Groups in the Younger and Older Groups}

Table 2 shows means of each variable in the alcohol intake groups of younger and older subjects. In the older group, heavy and very heavy drinkers were slightly but significantly younger than nondrinkers, while there were no significant differences in ages among the four alcohol groups in the younger group. In the younger group, BMI was significantly lower in light, heavy and very heavy drinkers than in nondrinkers and waist circumference was significantly smaller in light and heavy drinkers than in nondrinkers, while these differences were not found in the older group. Both in the younger and older groups, systolic and diastolic blood pressure was significantly higher in heavy and very heavy drinkers than in non- 
Table 2. Comparison of mean levels of each variable among the four drinker subgroups in the younger (Y) and older (O) subject groups

\begin{tabular}{|c|c|c|c|c|c|c|c|c|}
\hline \multirow{4}{*}{$\begin{array}{l}\text { Risk factor } \\
\text { Age, years }\end{array}$} & \multicolumn{8}{|c|}{ Drinker group } \\
\hline & \multicolumn{2}{|c|}{ nondrinker } & \multicolumn{2}{|c|}{$\begin{array}{l}\text { light } \\
(<22 \text { g/day })\end{array}$} & \multicolumn{2}{|c|}{$\begin{array}{l}\text { heavy } \\
(\geq 22,<44 \text { g/day })\end{array}$} & \multicolumn{2}{|c|}{$\begin{array}{l}\text { very heavy } \\
\text { ( } \geq 44 \text { g/day) }\end{array}$} \\
\hline & Y: & $39.2 \pm 2.8$ & Y: & $39.4 \pm 2.9$ & Y: & $39.7 \pm 3.0$ & Y: & $39.6 \pm 2.9$ \\
\hline & O: & $69.4 \pm 5.0$ & O: & $68.7 \pm 3.6$ & $\mathrm{O}:$ & $68.2 \pm 3.4^{* *}$ & O: & $67.5 \pm 2.9^{* *}$ \\
\hline \multirow[t]{2}{*}{ BMI } & $\mathrm{Y}:$ & $24.38 \pm 4.45$ & Y: & $23.16 \pm 3.24^{* *}$ & $\mathrm{Y}:$ & $23.32 \pm 3.08^{* *}$ & Y: & $23.28 \pm 3.15^{* *}$ \\
\hline & $\mathrm{O}:$ & $23.55 \pm 3.06$ & O: & $23.29 \pm 2.61$ & $\mathrm{O}:$ & $23.25 \pm 2.57$ & O: & $23.34 \pm 2.80$ \\
\hline \multirow[t]{2}{*}{ Waist circumference, $\mathrm{cm}$} & Y: & $84.4 \pm 11.3$ & Y: & $82.0 \pm 8.6^{*}$ & Y: & $82.7 \pm 8.3^{*}$ & Y: & $82.8 \pm 8.7$ \\
\hline & O: & $83.2 \pm 8.3$ & O: & $83.2 \pm 7.5$ & O: & $83.8 \pm 7.8$ & O: & $84.5 \pm 8.1$ \\
\hline \multirow[t]{2}{*}{ Systolic BP, mm Hg } & $\mathrm{Y}:$ & $124.0 \pm 15.9$ & Y: & $125.3 \pm 14.5$ & $\mathrm{Y}:$ & $127.1 \pm 15.0^{*}$ & Y: & $129.2 \pm 13.4^{* *}$ \\
\hline & O: & $133.5 \pm 15.9$ & O: & $135.9 \pm 15.4$ & O: & $136.7 \pm 15.0^{*}$ & O: & $141.3 \pm 16.8^{* *}$ \\
\hline \multirow[t]{2}{*}{ Diastolic BP, mm Hg } & Y: & $75.2 \pm 11.9$ & Y: & $75.8 \pm 10.8$ & Y: & $77.4 \pm 11.7^{*}$ & Y: & $78.8 \pm 10.1^{* *}$ \\
\hline & O: & $76.1 \pm 10.1$ & O: & $77.6 \pm 9.6$ & O: & $77.9 \pm 9.8^{*}$ & O: & $80.3 \pm 9.4^{* *}$ \\
\hline \multirow[t]{2}{*}{ HDL cholesterol, mg/dl } & Y: & $51.7 \pm 13.2$ & Y: & $57.9 \pm 14.1^{* *}$ & Y: & $61.9 \pm 15.5^{* *}$ & Y: & $64.8 \pm 19.1^{* *}$ \\
\hline & O: & $49.6 \pm 12.9$ & O: & $57.3 \pm 15.2^{* *}$ & $\mathrm{O}:$ & $60.2 \pm 15.6^{* *}$ & O: & $60.6 \pm 16.2^{* *}$ \\
\hline \multirow[t]{2}{*}{ Triglycerides, mg/dl } & Y: & $138.4 \pm 113.7$ & Y: & $128.0 \pm 85.0$ & Y: & $147.7 \pm 120.4$ & Y: & $155.5 \pm 113.4$ \\
\hline & O: & $129.1 \pm 79.7$ & O: & $122.5 \pm 114.0$ & O: & $125.1 \pm 102.9$ & O: & $151.0 \pm 168.6$ \\
\hline \multirow[t]{2}{*}{$\mathrm{HbA}_{1 \mathrm{c}}, \%$} & Y: & $5.13 \pm 0.93$ & Y: & $4.90 \pm 0.45^{* *}$ & Y: & $4.90 \pm 0.39^{* *}$ & Y: & $4.95 \pm 0.73^{*}$ \\
\hline & O: & $5.39 \pm 0.75$ & O: & $5.33 \pm 0.75$ & O: & $5.30 \pm 0.75$ & O: & $5.17 \pm 0.63^{* *}$ \\
\hline
\end{tabular}

Means with standard deviations of each variable are shown. Light drinkers: $<22$ g ethanol/day; heavy drinkers: $\geq 22$ and $<44$ g ethanol/day; very heavy drinkers: $\geq 44$ g ethanol/day. BP = blood pressure. ${ }^{*} \mathrm{p}<0.05 ;{ }^{* *} \mathrm{p}<0.01$ compared with nondrinkers.

drinkers and HDL cholesterol was significantly higher in light, heavy and very heavy drinkers than in nondrinkers. Both in the younger and older groups, triglycerides tended to be lower in light drinkers and higher in very heavy drinkers than in nondrinkers, although these differences were not significant. In the younger group, $\mathrm{HbA}_{1 \mathrm{c}}$ was significantly lower in light, heavy and very heavy drinkers than in nondrinkers, while in the older group, $\mathrm{HbA}_{1 \mathrm{c}}$ was significantly lower in very heavy drinkers but not in light and heavy drinkers than in nondrinkers.

\section{Comparison of the Prevalence of Each Risk Factor} for Atherosclerosis or Metabolic Syndrome among the Alcohol Intake Groups in the Younger and Older Groups

Table 3 shows the prevalence of each atherosclerotic risk factor or metabolic syndrome in the alcohol intake groups of younger and older subjects. In the younger group, the prevalence of large waist circumference was significantly lower in light drinkers than in nondrinkers, while in the older group, no significant difference was found between each drinker group and the nondrinker group. The prevalences of high blood pressure and low HDL cholesterol tended to increase and decrease, respectively, with increase in alcohol intake both in the younger and older groups. In the younger and older groups, the prevalence of high blood pressure was significantly higher in heavy and very heavy drinkers than in nondrinkers, and the prevalence of low HDL cholesterol was significantly lower in light, heavy and very heavy drinkers than in nondrinkers. Both in the younger and older subject groups, the prevalence of high triglycerides was significantly lower in light drinkers than in nondrinkers. In the younger group, the prevalence of high triglycerides was significantly higher in very heavy drinkers than in nondrinkers. The prevalence of high $\mathrm{HbA}_{1 \mathrm{c}}$ in the younger group was significantly lower in light and heavy drinkers than in nondrinkers but was not significantly different in very heavy drinkers and nondrinkers. The prevalence of high $\mathrm{HbA}_{1 \mathrm{c}}$ in the older group was significantly lower in very heavy drinkers than in nondrinkers but was not significantly different in light and heavy drinkers compared to that in nondrinkers. In the younger group, the prev- 
Table 3. Comparison of prevalence of each risk factor for atherosclerosis or metabolic syndrome (MetS) among nondrinker, light drinker, heavy drinker and very heavy drinker subgroups of the younger $(\mathrm{Y})$ and older $(\mathrm{O})$ subject groups

\begin{tabular}{|c|c|c|c|c|c|c|c|c|c|c|}
\hline \multirow{4}{*}{$\begin{array}{l}\text { Variable } \\
\text { Large waist circumference, } \%\end{array}$} & \multirow{2}{*}{\multicolumn{2}{|c|}{ Overall }} & \multicolumn{8}{|c|}{ Drinker group } \\
\hline & & & \multicolumn{2}{|c|}{ nondrinker } & \multicolumn{2}{|c|}{ light } & \multicolumn{2}{|c|}{ heavy } & \multicolumn{2}{|c|}{ very heavy } \\
\hline & $\mathrm{Y}:$ & 36.3 & $\mathrm{Y}:$ & 40.0 & Y: & $31.2^{*}$ & Y: & 34.8 & Y: & 36.3 \\
\hline & $\mathrm{O}:$ & $44.4^{\dagger \dagger}$ & $\mathrm{O}:$ & 44.4 & $\mathrm{O}:$ & 43.7 & $\mathrm{O}:$ & 45.0 & $\mathrm{O}:$ & 43.6 \\
\hline \multirow[t]{2}{*}{ High blood pressure, $\%$} & Y: & 45.5 & Y: & 39.8 & Y: & 43.7 & Y: & $47.6^{*}$ & $\mathrm{Y}:$ & $55.4^{* *}$ \\
\hline & $\mathrm{O}:$ & $76.8^{\dagger \dagger}$ & $\mathrm{O}:$ & 69.3 & $\mathrm{O}:$ & 75.8 & $\mathrm{O}:$ & $80.0^{* *}$ & O: & $88.2^{* *}$ \\
\hline \multirow[t]{2}{*}{ Low HDL cholesterol, \% } & Y: & & Y: & 15.6 & Y: & $5.6^{* *}$ & Y: & $4.7^{* *}$ & $\mathrm{Y}:$ & $4.4^{* *}$ \\
\hline & $\mathrm{O}:$ & $13.2^{\dagger+}$ & $\mathrm{O}:$ & 22.8 & O: & $12.1^{* *}$ & O: & $7.4^{* *}$ & $\mathrm{O}:$ & $5.9^{* *}$ \\
\hline \multirow[t]{2}{*}{ High triglycerides, \% } & $\mathrm{Y}:$ & 32.7 & $\mathrm{Y}:$ & 32.8 & Y: & $24.7^{*}$ & Y: & 32.5 & $\mathrm{Y}:$ & $41.7^{*}$ \\
\hline & O: & $26.0^{\dagger \dagger}$ & O: & 28.8 & $\mathrm{O}:$ & $20.9^{*}$ & O: & 24.5 & O: & 28.4 \\
\hline \multirow[t]{2}{*}{ High $\mathrm{HbA}_{1 \mathrm{c}}, \%$} & Y: & 3.8 & $\mathrm{Y}:$ & 6.8 & Y: & $0.5^{* *}$ & $\mathrm{Y}:$ & $2.0^{* *}$ & $\mathrm{Y}:$ & 4.4 \\
\hline & O: & $14.5^{\dagger \dagger}$ & O: & 15.6 & O: & 16.7 & O: & 14.9 & O: & $8.3^{*}$ \\
\hline \multirow[t]{2}{*}{ MetS by IDF, $\%$} & Y: & 13.7 & Y: & 16.0 & Y: & $9.8^{*}$ & Y: & $11.5^{*}$ & $\mathrm{Y}:$ & 17.6 \\
\hline & $\mathrm{O}:$ & $23.3^{\dagger+}$ & $\mathrm{O}:$ & 25.5 & O: & 22.8 & $\mathrm{O}:$ & 22.3 & $\mathrm{O}:$ & 21.1 \\
\hline \multirow[t]{2}{*}{ MetS by NCEP-ATP III, \% } & Y: & 13.8 & Y: & 16.2 & Y: & $9.8^{*}$ & Y: & $11.7^{*}$ & $\mathrm{Y}:$ & 17.6 \\
\hline & O: & $24.7^{\dagger \dagger}$ & $\mathrm{O}:$ & 27.2 & O: & 23.4 & O: & 23.7 & O: & 23.0 \\
\hline
\end{tabular}

The prevalence of each risk factor for atherosclerosis or metabolic syndrome is shown. Light drinkers: $<22 \mathrm{~g}$ ethanol/day; heavy drinkers: $\geq 22$ and $<44$ g ethanol/day; very heavy drinkers: $\geq 44 \mathrm{~g}$ ethanol/day. Marks denote significant differences from the nondrinker subgroup $\left({ }^{*} \mathrm{p}<0.05 ;{ }^{* *} \mathrm{p}<0.01\right)$ and the younger group $\left({ }^{+\dagger} \mathrm{p}<0.01\right)$.

alence of metabolic syndrome was significantly lower in light and heavy drinkers than in nondrinkers [IDF criteria: $16.0 \%$ (nondrinkers) vs. $9.8 \%$ (light drinkers) vs. $11.5 \%$ (heavy drinkers) vs. $17.6 \%$ (very heavy drinkers); NCEP-ATP III criteria: $16.2 \%$ (nondrinkers) vs. 9.8\% (light drinkers) vs. $11.7 \%$ (heavy drinkers) vs. $17.6 \%$ (very heavy drinkers)], while the prevalence of metabolic syndrome in the older group was not significantly different in any drinker groups compared to that in the nondrinker group [IDF criteria: $25.5 \%$ (nondrinkers) vs. $22.8 \%$ (light drinkers) vs. $22.3 \%$ (heavy drinkers) vs. $21.1 \%$ (very heavy drinkers); NCEP-ATP III criteria: 27.2\% (nondrinkers) vs. $23.4 \%$ (light drinkers) vs. $23.7 \%$ (heavy drinkers) vs. $23.0 \%$ (very heavy drinkers)].

\section{ORs of Each Drinker Group versus Nondrinker \\ Group for Each Atherosclerotic Risk Factor or \\ Metabolic Syndrome}

Table 4 shows ORs for each atherosclerotic risk factor or metabolic syndrome in the drinker groups vs. the nondrinker group. In the younger group, the OR vs. nondrinkers for large waist circumference was significantly low in light drinkers but was not significant in heavy and very heavy drinkers, while in the older group, the ORs were not significant in any drinker groups. Both in the younger and older groups, ORs vs. nondrinkers for high blood pressure and low HDL cholesterol tended to be higher and lower, respectively, with increase in alcohol intake and were significantly high and low, respectively, in light, heavy and very heavy drinkers. In the younger group, the OR vs. nondrinkers for high triglycerides was significantly high in very heavy drinkers but was not significant in light and heavy drinkers, while in the older group, the ORs were not significant in any drinker groups. ORs vs. nondrinkers for high $\mathrm{HbA}_{1 c}$ were significantly low in light and heavy drinkers in the younger subjects and significantly low in very heavy drinkers in the older subjects. In the younger group, the ORs vs. nondrinkers for metabolic syndrome, defined by criteria of IDF or NCEP ATP III, were significantly low in light and heavy drinkers but were not significant in very heavy drinkers [IDF criteria: light drinkers, 0.57 (0.34-0.95); heavy drinkers, 0.66 (0.45-0.96); very heavy drinkers, 1.11 (0.71-1.72); NCEP-ATP III criteria: light drinkers, 0.56 (0.34-0.94); heavy drinkers, $0.66(0.46-0.96)$; very heavy drinkers, $1.09(0.70-1.70)]$, while in the older group, these 
Table 4. OR of each drinker subgroup versus nondrinker subgroup for each risk factor for atherosclerosis or metabolic syndrome (MetS) in the younger $(\mathrm{Y})$ and older $(\mathrm{O})$ subject groups

\begin{tabular}{|c|c|c|c|c|c|c|c|}
\hline \multirow{4}{*}{$\begin{array}{l}\text { Risk factor } \\
\text { Large waist circumference }\end{array}$} & \multicolumn{7}{|c|}{ Drinker group } \\
\hline & \multirow{3}{*}{$\begin{array}{l}\text { nondrinker } \\
1\end{array}$} & \multicolumn{2}{|c|}{$\begin{array}{l}\text { light } \\
(<22 \text { g/day })\end{array}$} & \multicolumn{2}{|c|}{$\begin{array}{l}\text { heavy } \\
(\geq 22,<44 \text { g/day })\end{array}$} & \multicolumn{2}{|c|}{$\begin{array}{l}\text { very heavy } \\
(\geq 44 \text { g/day })\end{array}$} \\
\hline & & $\mathrm{Y}:$ & $0.68(0.49-0.96)^{*}$ & Y: & $0.78(0.60-1.01)$ & Y: & $0.85(0.60-1.20)$ \\
\hline & & O: & $1.01(0.73-1.40)$ & O: & $1.10(0.85-1.43)$ & O: & $1.10(0.78-1.56)$ \\
\hline \multirow[t]{2}{*}{ High blood pressure } & \multirow[t]{2}{*}{1} & $\mathrm{Y}:$ & $1.56(1.09-2.22)^{*}$ & Y: & $1.84(1.38-2.45)^{* *}$ & Y: & $2.70(1.86-3.91)^{* *}$ \\
\hline & & $\mathrm{O}:$ & $1.54(1.05-2.27)^{*}$ & $\mathrm{O}:$ & $2.00(1.46-2.73)^{* *}$ & O: & $3.97(2.42-6.52)^{* *}$ \\
\hline \multirow[t]{2}{*}{ Low HDL cholesterol } & \multirow[t]{2}{*}{1} & $\mathrm{Y}:$ & $0.36(0.19-0.69)^{* *}$ & Y: & $0.29(0.18-0.49)^{* *}$ & Y: & $0.24(0.12-0.51)^{* *}$ \\
\hline & & O: & $0.48(0.30-0.78)^{* *}$ & O: & $0.28(0.19-0.43)^{* *}$ & O: & $0.21(0.11-0.40)^{* *}$ \\
\hline \multirow[t]{2}{*}{ High triglycerides } & \multirow[t]{2}{*}{1} & $\mathrm{Y}:$ & $0.81(0.55-1.19)$ & $\mathrm{Y}:$ & $1.16(0.88-1.55)$ & Y: & $1.69(1.18-2.43)^{* *}$ \\
\hline & & $\mathrm{O}:$ & $0.69(0.46-1.03)$ & O: & $0.86(0.64-1.17)$ & O: & $1.08(0.73-1.59)$ \\
\hline \multirow[t]{2}{*}{ High $\mathrm{HbA}_{1 \mathrm{c}}$} & \multirow[t]{2}{*}{1} & $\mathrm{Y}:$ & $0.09(0.01-0.65)^{*}$ & Y: & $0.36(0.17-0.75)^{* *}$ & Y: & $0.86(0.39-1.92)$ \\
\hline & & $\mathrm{O}:$ & $1.17(0.75-1.83)$ & $\mathrm{O}:$ & $1.01(0.71-1.45)$ & O: & $0.48(0.27-0.86)^{*}$ \\
\hline \multirow[t]{2}{*}{ MetS by IDF } & \multirow[t]{2}{*}{1} & $\mathrm{Y}:$ & $0.57(0.34-0.95)^{*}$ & $\mathrm{Y}:$ & $0.66(0.45-0.96)^{*}$ & Y: & $1.11(0.71-1.72)$ \\
\hline & & O: & $0.88(0.60-1.29)$ & O: & $0.87(0.64-1.17)$ & O: & $0.81(0.54-1.22)$ \\
\hline \multirow[t]{2}{*}{ MetS by NCEP-ATP III } & \multirow[t]{2}{*}{1} & $\mathrm{Y}:$ & $0.56(0.34-0.94)^{*}$ & Y: & $0.66(0.46-0.96)^{*}$ & Y: & $1.09(0.70-1.70)$ \\
\hline & & O: & $0.83(0.57-1.20)$ & O: & $0.86(0.64-1.16)$ & O: & $0.82(0.56-1.22)$ \\
\hline
\end{tabular}

ORs with 95\% confidence intervals in parentheses are shown. ORs for low HDL cholesterol and high triglycerides were calculated after adjustment for age, history of smoking, $\mathrm{BMI}$ and history of therapy for dyslipidemia. ORs for high blood pressure and high $\mathrm{Hb} \mathrm{A}_{1 \mathrm{c}}$ were calculated after adjustment for age, history of smoking and BMI. ORs for large waist circumference and metabolic syndrome were calculated after adjustment for age and history of smoking. Light drinkers: $<22 \mathrm{~g}$ ethanol/day; heavy drinkers: $\geq 22 \mathrm{and}<44 \mathrm{~g}$ ethanol/ day; very heavy drinkers: $\geq 44$ g ethanol/day. Significant OR: * $\mathrm{p}<0.05 ;{ }^{* *} \mathrm{p}<0.01$.

ORs were not significant in any drinker groups [IDF criteria: light drinkers, $0.88(0.60-1.29)$; heavy drinkers, 0.87 (0.64-1.17); very heavy drinkers, 0.81 (0.54-1.22); NCEP-ATP III criteria: light drinkers, 0.83 (0.57-1.20); heavy drinkers, $0.86(0.64-1.16)$; very heavy drinkers, $0.82(0.56-1.22)]$.

\section{Discussion}

This is the first study showing that the relationship between alcohol intake and metabolic syndrome is influenced by age. In younger subjects, an alcohol intake $<44 \mathrm{~g}$ ethanol/day was associated with a lower risk for metabolic syndrome, but no significant association between alcohol intake and metabolic syndrome was found in older subjects. Two different sets of criteria, those by IDF and NCEP ATP III, were used to define metabolic syndrome, but the results for the relationship between alcohol intake and prevalence of metabolic syndrome were not different in the analyses using these two sets of criteria. Thus, a beneficial effect of alcohol drinking on the risk for metabolic syndrome was found only in younger subjects. Regarding relationships between alcohol intake and risk factors related to metabolic syndrome, the associations of alcohol intake with higher blood pressure and higher HDL cholesterol were similar in the younger and older groups. On the other hand, the associations of alcohol intake with lower BMI, smaller waist circumference, higher triglycerides, and lower $\mathrm{HbA}_{1 \mathrm{c}}$ were more prominent in the younger group than in the older group. Thus, the difference in the relationship of alcohol intake with metabolic syndrome between the younger and older subject groups is mainly due to associations of alcohol intake (light or heavy drinkers) with lower risks for large waist circumference and high $\mathrm{HbA}_{1 c}$ in the younger subject group but not in the older group. The reason for the differences between the younger and older groups in the relationships of alcohol intake with waist circumference and $\mathrm{HbA}_{1 \mathrm{c}}$ are obscure, and there have been few reports on effects of age on relationships of alcohol drinking with obesity and diabetes. Since obesity is a major risk factor 
for diabetes, it is speculated that the common pathogenesis underlying obesity and diabetes is affected by alcohol drinking differently in younger and older men; however, further studies are needed to clarify this hypothesis.

Although metabolic syndrome is known as a potent risk factor for ischemic heart disease and stroke in the elderly [21,22], there have been only a few studies on the relationship between alcohol consumption and metabolic syndrome in the elderly. Moreover, the results of previous studies on the relationships between alcohol intake and metabolic syndrome in a general population are controversial [6-9]. In a study using Japanese subjects, the prevalence of metabolic syndrome was significantly higher in heavy drinkers than in non- and light drinkers, although non- and light drinkers were analyzed together and no comparison was made between non- and light drinkers and between non- and heavy drinkers [23]. Using elderly subjects, both British and Italian groups have recently shown no significant associations of alcohol consumption with incidence and prevalence of metabolic syndrome in the elderly $[24,25]$. These findings agree with the results of the present study. However, it is unknown whether age influences the alcohol-metabolic syndrome relationship. The present study demonstrated an age-dependent difference in the relationship between alcohol consumption and metabolic syndrome by using younger and older groups matched for alcohol intake and smoking history, which is known to confound the relationships of alcohol intake with blood pressure and serum lipids $[26,27]$. As a result, there are no beneficial effects of alcohol drinking on the metabolic syndrome in the elderly, while light to moderate alcohol intake is associated with a lower risk for metabolic syndrome in young people. Therefore, it is thought that age should be taken into account when relationships of alcohol intake with metabolic syndrome and atherosclerotic risk factors are considered. Age difference may, in part, explain the discrepant results of previous studies on the relationship between alcohol intake and metabolic syndrome.

There are some limitations of this study. One limitation is the use of $\mathrm{HbA}_{1 \mathrm{c}}$ level, instead of fasting plasma glucose, for diagnosis of metabolic syndrome. Although age, history of smoking and BMI were adjusted in the logistic regression analysis in this study, the relationship between alcohol and metabolic syndrome is confounded by other lifestyle-related factors such as diet, nutrition and physical activity, for which information was not available in the database used in this study. Socioeconomic characteristics of subjects, such as education level, income and martial status, that influence health behavior including alcohol drinking and are thus possible confounders for the relationship between alcohol intake and metabolic syndrome were not included in the questionnaire used in this study. Only history of current smoking status was asked in the questionnaire, and thus no information on ex-smokers and duration of smoking history is also a limitation of this study. Only drinkers who drank alcohol almost every day were used as drinker subjects, and occasional drinkers were excluded from subjects of this study. It is therefore speculated that drinker subjects had quite a long history of alcohol drinking, although no detailed information on the duration of alcohol consumption at the time of the health checkup was available from the database used in this study. Polymorphism of alcohol-metabolizing enzymes is well known in Asians $[28,29]$ and possibly confounds the relationship between alcohol intake and metabolic syndrome in the present study, although controversial results were obtained in previous studies on the effects of the polymorphism on the relationship between alcohol intake and an atherosclerotic risk factor such as blood pressure [30-34]. A gender-related difference in the alcohol-blood pressure relationship has been shown recently [35]. However, only male subjects were used in the present study, and it remains to be determined whether age also influences the relationship between alcohol and metabolic syndrome in women. The present study is a cross-sectional study using only two different age groups, and prospective studies using various age groups including younger subjects than those in this study are needed to clarify causal relationships between alcohol and metabolic syndrome at different ages.

In conclusion, the results showed that alcohol intake was associated with a lower risk for metabolic syndrome in young men but not in elderly men, thus suggesting that the relationship between alcohol intake and metabolic syndrome depends on age.

\section{Acknowledgement}

This study was supported by a Grant-in-Aid for Scientific Research from the Japan Society for the Promotion of Science (No. 21390211).

\section{Disclosure Statement}

No conflicts of interest exist. 


\section{References}

1 Gaziano JM, Buring JE, Breslow JL, Goldhaber SZ, Rosner B, VanDenburgh M, Willett W, Hennekens $\mathrm{CH}$ : Moderate alcohol intake, increased levels of high-density lipoprotein and its subfractions, and decreased risk of myocardial infarction. N Engl J Med 1993;329:1829-1834.

\2 Rimm EB, Williams P, Fosher K, Criqui M, Stampfer MJ: Moderate alcohol intake and lower risk of coronary heart disease: metaanalysis of effects on lipids and haemostatic factors. BMJ 1999;319:1523-1528.

>3 Meade TW, Vickers MV, Thompson SG, Stirling Y, Haines AP, Miller GJ: Epidemiological characteristics of platelet aggregability. BMJ (Clin Res Ed) 1985;290:428-432.

$\checkmark 4$ Klatsky AL: Alcohol and hypertension. Clin Chim Acta 1996;246:91-105.

5 Rehm J, Room R, Monteiro M, Gmel G, Graham K, Rehn N, Sempos CT, Jernigan D: Alcohol as a risk factor for global burden of disease. Eur Addict Res 2003;9:157-164.

-6 Freiberg MS, Cabral HJ, Heeren TC, Vasan RS, Curtis Ellison R: Alcohol consumption and the prevalence of the Metabolic Syndrome in the US: a cross-sectional analysis of data from the Third National Health and Nutrition Examination Survey. Diabetes Care 2004;27:2954-2959.

$\checkmark 7$ Yoon YS, Oh SW, Baik HW, Park HS, Kim WY: Alcohol consumption and the metabolic syndrome in Korean adults: the 1998 Korean National Health and Nutrition Examination Survey. Am J Clin Nutr 2004;80:217224.

8 Baik I, Shin C: Prospective study of alcohol consumption and metabolic syndrome. Am J Clin Nutr 2008;87:1455-1463.

9 Goude D, Fagerberg B, Hulthe J, AIR Study Group: Alcohol consumption, the metabolic syndrome and insulin resistance in 58-yearold clinically healthy men (AIR Study). Clin Sci (Lond) 2002;102:345-352.

10 Kotchen JM, McKean HE, Kotchen TA: Blood pressure trends with aging. Hypertension 1982;4:III128-III134.

-11 The Lipid Research Clinics Program Epidemiology Committee: Plasma lipid distributions in selected North American populations: the Lipid Research Clinics Program Prevalence Study. Circulation 1979;60:427439.

12 Meigs JB: Epidemiology of the metabolic syndrome, 2002. Am J Manag Care 2002; 8:S283-S292.

-13 Alberti KG, Zimmet P, Shaw J, IDF Epidemiology Task Force Consensus Group: The metabolic syndrome - a new worldwide definition. Lancet 2005;366:1059-1062.
14 Expert Panel on Detection, Evaluation, and Treatment of High Blood Cholesterol in Adults: Executive Summary of The Third Report of The National Cholesterol Education Program (NCEP) Expert Panel on Detection, Evaluation, and Treatment of High Blood Cholesterol In Adults (Adult Treatment Panel III). JAMA 2001;285:2486-2497.

15 Chobanian AV, Bakris GL, Black HR, Cushman WC, Green LA, Izzo JL Jr, Jones DW Materson BJ, Oparil S, Wright JT Jr, Roccella EJ, National High Blood Pressure Education Program Coordinating Committee: The Seventh Report of the Joint National Committee on Prevention, Detection, Evaluation, and Treatment of High Blood Pressure: the JNC 7 report. JAMA 2003;289:2560-2572.

16 European Society of Hypertension-European Society of Cardiology Guidelines Committee: 2003 European Society of Hypertension-European Society of Cardiology guidelines for the management of arterial hypertension. J Hypertens 2003;21:1011-1053.

17 Anonymous: Metabolic syndrome-definition and diagnostic criteria in Japan (in Japanese). J Jpn Soc Int Med 2005;94:794-809.

18 Hara K, Matsushita Y, Horikoshi M, Yoshiike N, Yokoyama T, Tanaka H, Kadowaki T: A proposal for the cutoff point of waist circumference for the diagnosis of metabolic syndrome in the Japanese population. Diabetes Care 2006;29:1123-1124.

19 Miyatake N, Wada J, Matsumoto S, Nishikawa $H$, Makino $H$, Numata T: Re-evaluation of waist circumference in metabolic syndrome: a comparison between Japanese men and women. Acta Med Okayama 2007;61: 167-169.

20 Ishida K, Okanishi A, Takashina S: A study on screening test of diabetes, based on correlation between FPG, $\mathrm{HbA}_{1 \mathrm{c}}$ and $2 \mathrm{hPG}$ at $75 \mathrm{~g}$ OGTT (in Japanese). J Japan Diab Soc 1998;41(suppl 2):A65-A67.

21 Milionis HJ, Rizos E, Goudevenos J, Seferiadis K, Mikhailidis DP, Elisaf MS: Components of the metabolic syndrome and risk for first-ever acute ischemic nonembolic stroke in elderly subjects. Stroke 2005;36:13721376.

22 Scuteri A, Najjar SS, Morrell CH, Lakatta EG: The metabolic syndrome in older individuals: prevalence and prediction of cardiovascular events: the Cardiovascular Health Study. Diabetes Care 2005;28:882-887.

23 Urashima M, Wada T, Fukumoto T, Joki M, Maeda T, Hashimoto H, Oda S: Prevalence of metabolic syndrome in a 22,892 Japanese population and its associations with lifestyle. JMAJ 2005;48:441-450.

24 Wannamethee SG, Shaper AG, Whincup $\mathrm{PH}$ : Modifiable lifestyle factors and the metabolic syndrome in older men: effects of lifestyle changes. J Am Geriatr Soc 2006;54: 1909-1914.
25 Buja A, Scafato E, Sergi G, Maggi S, Suhad MA, Rausa G, Coin A, Baldi I, Manzato E, Galluzzo L, Enzi G, Perissinotto E, ILSA Working Group: Alcohol consumption and metabolic syndrome in the elderly: results from the Italian longitudinal study on aging. Eur J Clin Nutr 2010;64:297-307.

26 Wakabayashi I: Modification of the association of alcohol drinking with blood pressure by cigarette smoking. Blood Press 2008;17: 87-93.

27 Wakabayashi I: Associations of alcohol drinking and cigarette smoking with serum lipid levels in healthy middle-aged men. Alcohol Alcohol 2008;43:274-280.

28 Mizoi Y, Ijiri I, Tatsuno Y, Kijima T, Fujiwara S, Adachi J, Hishida S: Relationship between facial flushing and blood acetaldehyde levels after alcohol intake. Pharmacol Biochem Behav 1979;10:303-311.

29 Harada S, Agarwal DP, Goedde HW: Aldehyde dehydrogenase deficiency as cause of facial flushing reaction to alcohol in Japanese. Lancet 1981;2:982.

30 Okayama A, Ueshima H, Yamakawa M, Kita Y: Low $-K_{m}$ aldehyde dehydrogenase deficiency does not influence the elevation of blood pressure by alcohol. J Hum Hypertens 1994;8:205-208.

31 Tsuritani I, Ikai E, Date T, Suzuki Y, Ishizaki M, Yamada Y: Polymorphism in ALDH2genotype in Japanese men and the alcoholblood pressure relationship. Am J Hypertens 1995;8:1053-1059.

32 Itoh T, Matsumoto M, Nakamura M, Okada A, Shirahashi N, Hougaku H, Hashimoto $\mathrm{H}$, Sakaguchi M, Handa N, Takeshita T, Morimoto K, Hori M: Effects of daily alcohol intake on the blood pressure differ depending on an individual's sensitivity to alcohol: oriental flushing as a sign to stop drinking for health reasons. J Hypertens 1997;15:12111217.

33 Nakamura Y, Amamoto K, Tamaki S, Okamura T, Tsujita Y, Ueno Y, Kita Y, Kinoshita $M$, Ueshima $H$ : Genetic variation in aldehyde dehydrogenase- 2 and the effect of alcohol consumption on cholesterol levels. Atherosclerosis 2002;164:171-177.

34 Wakabayashi I: Sensitivity of circulatory response to alcohol influences the relationship between alcohol consumption and blood pressure in Orientals. Blood Press 2005; 14 : 238-244.

35 Wakabayashi I: Influence of gender on the association of alcohol drinking with blood pressure. Am J Hypertens 2008;21:13101317. 